\title{
The role of a sequencing-based clinical intestinal screening test in patients at high-risk for Clostridium difficile and other pathogens: a case report
}

Maureen Hitschfeld ${ }^{1}$, Elena Tovar', Sarah Gupta', Elisabeth M. Bik ${ }^{1}$ (D, Christina Palmer ${ }^{1}$, Michael C. Hoaglin ${ }^{1}$, Daniel E. Almonacid ${ }^{1}$, Jessica Richman ${ }^{1}$ and Zachary S. Apte ${ }^{1,2^{*}}$

\begin{abstract}
Background: Hospitalization and antibiotic treatment can put patients at high risk for Clostridium difficile infection, where a disturbance of the gut microbiome allows for Clostridium difficile proliferation and associated symptoms, including mild, moderate, or severe diarrhea. Clostridium difficile infection is challenging to treat, often recurrent, and leads to almost 30,000 annual deaths in the USA alone. Here we present a case where SmartGut ${ }^{\mathrm{TM}}$, an at-home, self-administered sequencing-based clinical intestinal screening test, was used to identify the presence of Clostridium difficile in a patient with worsening diarrhea. Identification of this pathogen and subsequent treatment led to a significant improvement in symptoms.

Case presentation: The patient is a 29-year-old white woman with a history of severe irritable bowel syndrome with diarrhea, hemorrhoidectomy, and anal sphincterotomy complicated by a perianal fistula and perirectal abscesses that required extended courses of broad-spectrum antibiotics. In June 2016, she developed intermittent Clostridium difficile infections, which required continued antibiotic use. Months later she used an at-home, selfadministered, intestinal microbial test, the first of which was negative for the presence of Clostridium difficile, but it detected the relative abundance of microbes associated with irritable bowel syndrome outside the healthy reference ranges. In the subsequent 2 months after the negative Clostridium difficile result, her gastrointestinal symptoms worsened dramatically. A second microbiome test resulted in a positive Clostridium difficile finding and continued abnormal microbial parameters, which led the treating physician to refer her to a gastroenterologist. Additional testing confirmed the presence of Clostridium difficile with a toxin-positive strain. She received treatment immediately and her gastrointestinal symptoms improved significantly over the next week.

Conclusions: This case report suggests that more frequent DNA testing for Clostridium difficile infections may be indicated in patients that are at high-risk for Clostridium difficile infection, especially for patients with irritable bowel syndrome, and those who undergo gastrointestinal surgery and/or an extended antibiotic treatment. This report also shows that such testing could be effectively performed using at-home, self-administered sequencing-based clinical intestinal microbial screening tests. Further research is needed to investigate whether the observations reported here extrapolate to a larger cohort of patients.
\end{abstract}

Keywords: Clostridium difficile, Irritable bowel syndrome, Screening test, Gastrointestinal surgery, Comorbidity, Multimorbidity, IBS, CDI

\footnotetext{
* Correspondence: zachary.apte@ucsf.edu

'uBiome, San Francisco, CA, USA

${ }^{2}$ University of California San Francisco, San Francisco, CA, USA
}

(c) The Author(s). 2019 Open Access This article is distributed under the terms of the Creative Commons Attribution 4.0 International License (http://creativecommons.org/licenses/by/4.0/), which permits unrestricted use, distribution, and reproduction in any medium, provided you give appropriate credit to the original author(s) and the source, provide a link to the Creative Commons license, and indicate if changes were made. The Creative Commons Public Domain Dedication waiver (http://creativecommons.org/publicdomain/zero/1.0/) applies to the data made available in this article, unless otherwise stated. 


\section{Background}

The human gut microbiome consists of trillions of microorganisms that populate the human gut, and its genome is approximately 100 times larger than the human genome [1]. It is considered by some to act as an organ due to the number of physiological functions that it performs for the host [2]. Under normal conditions, commensal microbes and their hosts enjoy a symbiotic relationship. In addition, a greater diversity of microorganisms is generally an indicator for gut health, presumably because it offers greater resistance to perturbation $[3,4]$. Intestinal dysbiosis refers to identifiable abnormality of the gut microbiota, either due to low microbial diversity, suboptimal levels of commensal beneficial microbes, excess of potentially harmful microorganisms, or presence of pathogenic microbes [5, 6]. Maladaptive alterations of the microbiome composition result in deficient functions, which are associated with various prevalent conditions, such as irritable bowel syndrome (IBS), inflammatory bowel disease (IBD), type 2 diabetes, prediabetes, obesity, non-alcoholic fatty liver disease, atherosclerosis, cardiovascular disease, kidney stones, among others [7-13]. Interestingly, the host interactions with the gut microbiome and its composition are not static, but rather dynamic and modifiable over time [14]. Diet, medication, and lifestyle are important determinants of microbial composition [15-17]. However, the largest and most immediate effects on microbial composition are related to the use of antibiotics, which may negatively affect the composition and function of the gut microbiota and consequently have an impact on patient well-being [18].

In the USA, IBS is the most common functional gastrointestinal (GI) disorder, with a reported prevalence between 10 and 25\%; women exhibit prevalence rates 1.5-fold to 3-fold higher than men [19]. This chronic condition is characterized by abdominal pain associated with bowel dysfunction. Although IBS etiology is not completely understood, it is regarded as multifactorial. Contributing factors include intestinal motility, inflammation, genetics, immunology, psychology, and diet [20-22]. There are several subtypes of IBS, including IBS with constipation (IBS-C), IBS with diarrhea (IBS-D), mixed IBS (IBS-M), and unclassified (IBS-U) [23]. Initial treatment may include dietary and lifestyle changes. In particular, the low fermentable oligosaccharides, disaccharides, monosaccharides, and polyols (FODMAP) diet shows benefits in the management of IBS [24, 25]. Cognitive behavioral therapy has also been shown to be successful in managing IBS symptoms because anxiety and depression are commonly seen in patients with IBS [26]. Patients with more severe symptoms may also benefit from pharmacologic therapy to address predominant symptoms. A diagnosis of IBS is difficult to make. It has been estimated that up to $75 \%$ of cases of IBS go undiagnosed [27]. Studies show that patients with IBS have an underlying alteration of their gut microbiota composition [28-31]. For instance, it is known that abundance of the genus Veillonella is positively associated with IBS, while the relative abundances of genera Alistipes, Bifidobacterium, and Lactobacillus and the species Collinsella aerofaciens are inversely associated with IBS [16, 32-35].

Clostridium difficile is currently the leading cause of infectious nosocomial diarrhea in the USA; the incidence and severity of $C$. difficile infection (CDI) are increasing and are associated with increased health care costs [36]. C. difficile is an opportunistic pathogen, with toxigenic strains known to cause high levels of morbidity and mortality. There are a number of well-known risk factors that have been linked to CDI, including exposure to antibiotics and gastric acid suppressants, hospitalization, GI surgery, working in a health care setting, and the presence of underlying disease or immunosuppression $[37,38]$. According to the Centers for Disease Control and Prevention, $C$. difficile was responsible for almost half a million infections and was associated with approximately 29,000 deaths in 2011 [39]. Toxicity from CDI is mediated by two exotoxins: toxin A and toxin B [40]. Colonization of the gut microbiota with $C$. difficile can be innocuous and asymptomatic; however, if the normal intestinal microbial architecture is disrupted, proliferation of opportunistic $C$. difficile may occur. There is evidence that CDI risk in C. difficile carriers is nine times higher than in non-carriers [41], and in healthy adult patient populations, as many as $15 \%$ of people may be colonized with $C$. difficile; prevalence rates appear to vary widely depending on the population [42].

There are limited data on what role CDI may play in patients with IBS. A cohort study showed that a new-onset of IBS is common after CDI. Infection duration, anxiety, and higher body mass index (BMI) were found to be associated with higher risk of the diagnosis of $C$. difficile in patients with post-infectious IBS [43]. Another study suggested that a subpopulation of patients with IBS in the absence of known risk factors for $C$. difficile may be susceptible and predisposed to CDI [44]. In this small study, C. difficile incidence among patients with IBS (5 out of 87) was higher than in the control group (1 out of 88), albeit not statistically significant, and the positive cases were found among all three IBS subtypes [44].

Here we present a case of a patient with a diagnosis of IBS-D, who used an at-home, self-administered, sequencing-based clinical intestinal microbial screening test (SmartGut ${ }^{\mathrm{tm}}$, uBiome Inc., San Francisco, USA) to identify the presence of $C$. difficile in the setting of multiple chronic conditions. Treatment for C. difficile led to resolution of her symptoms. 


\section{Case presentation}

This patient is a 29-year-old white woman from the USA with a medical history significant for severe IBS-D (diagnosed at age 12) and anxiety disorder. In July 2015, she presented with severe bleeding hemorrhoids secondary to IBS, which required hemorrhoidectomy and anal sphincterotomy in August 2015. The week before the surgery she developed pharyngitis and was treated with azithromycin, which resulted in mucousy diarrhea and abdominal discomfort. She tested negative for $C$. difficile antigen and toxins at that time.

A week after surgery, she developed a perirectal abscess that had formed at the site of the sphincterotomy and was prescribed orally administered ciprofloxacin. Despite moderate symptom improvement, in September 2015 she required an abscess incision and drainage procedure and Penrose drain insertion. Prior to the surgery she was given a single dose of clindamycin. An additional 2-week course of ciprofloxacin and metronidazole was then prescribed. In late September 2015 she was admitted to the hospital for two nights due to further complications related to the abscess and was then diagnosed as having a perianal fistula.

In November 2015, she was prescribed clindamycin for an episode of group C streptococcal-positive pharyngitis. In late November 2015, she was also diagnosed as having Ehlers-Danlos syndrome, which according to her medical record may partially explain the poor wound healing from the perirectal abscess. In December 2015, her fistula required an anus seton placement. She was treated with multiple courses of ciprofloxacin and metronidazole off and on from December 2015 to January 2016.

In January 2016, following up on her recurrent pharyngitis, she was diagnosed as having chronic tonsillitis which led to tonsillectomy. In February 2016, 2 weeks after the surgery she was prescribed clindamycin. At the beginning of March 2016, she was diagnosed as having bacterial vaginosis and was prescribed orally administered metronidazole. A week later she was diagnosed as having vaginal candidiasis and was prescribed orally administered fluconazole. In April 2016, she complained of dysuria and was prescribed ciprofloxacin. After 2 days, when urine analysis results came back negative, she was asked by her physician to stop the treatment.

In June 2016, she presented for follow-up with ongoing diarrhea and abdominal pain. She was diagnosed as having $C$. difficile diarrhea, her antigen and toxins laboratory results were indeterminate, and a toxigenic strain was confirmed by polymerase chain reaction (PCR). She was prescribed a 6-week course of orally administered vancomycin. After a week of treatment her symptoms worsened, and following discussion with her gastroenterologist her treatment was switched to a 2-week course of metronidazole. Hours later, she was admitted to the hospital for a 4-day period for colitis. Her $C$. difficile antigen and toxin test returned negative during her admission. She received intravenously administered metronidazole treatment during her hospitalization. Her symptoms improved during her hospital stay, with 1-2 soft bowel movements a day. At discharge her metronidazole course was stopped and she was again prescribed vancomycin, which she took for over a month. She continued to experience GI irregularity (3-5 bowel movements a day) beyond what she had experienced secondary to her IBS prior to her surgeries. In March 2017, she was prescribed rifaximin for 2 weeks to treat chronic diarrhea.

In November 2017, she was prescribed a series of clinical intestinal tests (SmartGut ${ }^{\mathrm{TM}}$, uBiome Inc., San Francisco, USA) with the instructions to administer the test at home whenever she was experiencing a noticeable change of GI symptoms, then follow-up with her health care provider to discuss the results. This sequencing-based test requires that patients use a sterile swab to transfer a small amount of fecal material from toilet paper into a vial containing a lysis and stabilization buffer that preserves the microbial DNA for transport by mail back to the laboratory for processing, which involves DNA extraction, $16 \mathrm{~S}$ ribosomal RNA (rRNA) gene amplification, and sequencing [45]. She first used this test in November 2017, about a month after completing a 2 -week course of rifaximin. The results revealed a number of microbial organisms that were outside the healthy reference ranges, but she was negative for all pathogenic organisms included in the test, including C. difficile (Fig. 1).

Between November and December 2017, her GI symptoms worsened considerably; her daily bowel movements increased from 3-4 to 6-10, stool consistency became more mucous-like and gelatinous, and she was experiencing more pain with defecation. She re-tested with SmartGut $^{\mathrm{TM}}$ test again in January 2018. Her results continued to reveal a number of microbial organisms outside the healthy range and, this time, her sample also indicated the presence of $C$. difficile (Fig. 2). She immediately contacted her primary care provider, who re-tested her for $C$. difficile and confirmed indeterminate CDI by antigen and toxins $\mathrm{A}$ and $\mathrm{B}$. Additional PCR testing at a regional laboratory confirmed the sample was positive for a toxigenic $C$. difficile strain. As a result of testing, her clinician started her on fidaxomicin; her symptoms improved rapidly. By April 2018, she had returned to her baseline in regard to her IBS-related GI symptoms with no blood in her stools.

In addition, the second SmartGut ${ }^{\mathrm{Ts}}$ sample was tested for toxins $\mathrm{A}$ and $\mathrm{B}$ by sequencing at uBiome Inc. laboratory in San Francisco, USA, which resulted positive for both and confirmed the toxigenic nature of the $C$. difficile strain. 


\begin{tabular}{|lll|}
\hline Pat Pathogens & Positive: 0 of 3 species, 0 of 2 genera \\
\hline Pathogenic Species & Clostridium difficile & 0 Negative \\
\hline & Salmonella enterica & 0 Negative \\
\hline Vibrio cholerae & 0 Negative \\
\hline Pathogenic Genera & Campylobacter & 0 Negative \\
\hline & Escherichia-Shigella & 0 Negative \\
\hline
\end{tabular}

\begin{tabular}{|c|c|c|c|c|}
\hline Diarrhea & & & & \\
\hline \multirow[t]{7}{*}{ Associated } & 蔯 & Clostridium difficile [1-3] & 0 & Negative \\
\hline & ; & Campylobacter $[4,5]$ & 0 & Negative \\
\hline & 茹 & Escherichia-Shigella [6-10] & 0 & Negative \\
\hline & 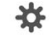 & Salmonella enterica [11-15] & $\mathrm{O}$ & Negative \\
\hline & ; & Vibrio cholerae $[16,17]$ & $\mathrm{O}$ & Negative \\
\hline & & Clostridium $[18,19]$ & 0 & Negative \\
\hline & & Bacteroides fragilis $[20,21]$ & 0 & Negative \\
\hline \multirow[t]{2}{*}{ Inversely associated } & & Lactobacillus [22] & $:$ & Normal \\
\hline & & Microbial Diversity $[23,24]$ & $:$ & Normal \\
\hline
\end{tabular}

\begin{tabular}{|c|c|c|c|c|c|}
\hline \multicolumn{6}{|c|}{ Irritable Bowel Syndrome } \\
\hline \multirow[t]{4}{*}{ Associated } & $\not$ & Salmonella enterica [25] & 0 & Negative & \\
\hline & ஆ & Campylobacter [25] & 0 & Negative & \\
\hline & * & Escherichia-Shigella [25] & 0 & Negative & \\
\hline & & Veillonella [26] & 0 & Negative & \\
\hline \multirow[t]{4}{*}{ Inversely associated } & & Alistipes [27] & $:$ & Low & A \\
\hline & & Bifidobacterium [28] & $:$ & Low & $\boldsymbol{A}$ \\
\hline & & Collinsella aerofaciens [28-30] & $:$ & Low & $\boldsymbol{A}$ \\
\hline & & Lactobacillus $[26,28]$ & $:$ & Normal & \\
\hline
\end{tabular}

Fig. 1 Selected results from the first SmartGut ${ }^{\text {TM }}$ test report taken by the patient in November 2017 (Clostridium difficile negative). Three relevant parts of the clinical intestinal test SmartGut ${ }^{\mathrm{TM}}$ report generated after sample analysis are shown here: pathogens section, diarrhea from the infections section, and irritable bowel syndrome from the gut conditions section. The actual report is much more comprehensive and includes: other gut conditions such as inflammatory bowel disease, including ulcerative colitis and Crohn's disease, and gastrointestinal symptoms; diet and lifestyle conditions, such as obesity, kidney stones, type 2 diabetes, non-alcoholic fatty liver disease, and prediabetes; and cardiovascular health conditions, such as atherosclerosis and cardiovascular disease, among others

\section{Discussion and conclusions}

The patient had multiple risk factors for C. difficile colonization and overgrowth, such as several out-patient visits, hospitalizations, and previous GI surgery [46]. In this case, it is particularly important to note that repeat administration of combination and/or long-term broadspectrum antibiotics may have contributed to changes in the patient's intestinal microbiome, potentially contributing to $C$. difficile proliferation. During treatment with antibiotics, bacterial organisms that are susceptible to the antibiotics decrease in abundance or disappear, which potentially generates a microenvironment that enables $C$. difficile to thrive and increase in relative abundance, which could lead to the development of CDI [47-49]. Hence, it is recommended to prescribe antibiotics prudently. An example of a successful antibiotic stewardship intervention reducing CDIs in Scotland was avoiding the use of " $4 \mathrm{C}$ " antibiotics: fluoroquinolones (for example, ciprofloxacin), 


\begin{tabular}{|c|c|c|c|}
\hline to Pathogens & Positive: 1 of 3 species, 0 of 2 genera & & \\
\hline \multirow[t]{3}{*}{ Pathogenic Species } & Clostridium difficile & O & Positive \\
\hline & Salmonella enterica & 0 & Negative \\
\hline & Vibrio cholerae & 0 & Negative \\
\hline \multirow[t]{2}{*}{ Pathogenic Genera } & Campylobacter & 0 & Negative \\
\hline & Escherichia-Shigella & 0 & Negative \\
\hline
\end{tabular}

\begin{tabular}{|c|c|c|c|c|c|}
\hline Diarrhea & & & & & \\
\hline \multirow[t]{7}{*}{ Associated } & \% & Clostridium difficile [1-3] & 0 & Positive & $\mathbf{A}$ \\
\hline & \$ & Campylobacter $[4,5]$ & 0 & Negative & \\
\hline & * & Escherichia-Shigella [6-10] & 0 & Negative & \\
\hline & * & Salmonella enterica [11-15] & 0 & Negative & \\
\hline & 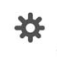 & Vibrio cholerae $[16,17]$ & 0 & Negative & \\
\hline & & Clostridium $[18,19]$ & 0 & Negative & \\
\hline & & Bacteroides fragilis $[20,21]$ & 0 & Negative & \\
\hline \multirow[t]{2}{*}{ Inversely associated } & & Lactobacillus [22] & $:$ & Normal & \\
\hline & & Microbial Diversity $[23,24]$ & $:$ & Normal & \\
\hline
\end{tabular}

\begin{tabular}{|c|c|c|c|c|}
\hline \multicolumn{5}{|c|}{ Irritable Bowel Syndrome } \\
\hline \multirow[t]{4}{*}{ Associated } & * Salmonella enterica[25] & 0 & Negative & \\
\hline & Campylobacter [25] & 0 & Negative & \\
\hline & * Escherichia-Shigella [25] & 0 & Negative & \\
\hline & Veillonella [26] & O & Negative & \\
\hline \multirow[t]{4}{*}{ Inversely associated } & Alistipes [27] & $:$ & Low & A \\
\hline & Bifidobacterium [28] & $:$ & Low & A \\
\hline & Collinsella aerofaciens [28-30] & $:$ & Low & $\Delta$ \\
\hline & Lactobacillus $[26,28]$ & $:$ & Normal & \\
\hline
\end{tabular}

Fig. 2 Selected results from the second SmartGut ${ }^{\mathrm{TM}}$ test report taken by the patient in January 2018 (Clostridium difficile positive)

clindamycin, co-amoxiclav, and third-generation cephalosporins, and using narrow-spectrum antibiotics instead (for example, fidaxomicin) [48]. Hence, reported new IBS treatment concepts involving the use of antibiotics need attention [50].

Importantly, this case study suggests that in high-risk populations, such as those repeatedly treated with antibiotics, there may be a need for more frequent and convenient testing for $C$. difficile and possibly for other GI pathogens as well. It makes sense that a self-administered, at-home, non-invasive test is an ideal adjunct solution for regular monitoring between scheduled appointments, particularly in patients who are already burdened by multiple visits to their health care providers or even by hospitalizations. Patients with known risk factors for CDI such as immunodeficiency, cystic fibrosis, and diabetes, or prolonged administration of antibiotics, proton pump inhibitors, and antidiarrheal medication [46] may need to be screened more often and may benefit from at-home testing.

Further investigation is greatly needed to understand the potential connection between the human intestinal microbiome, IBS, and the presence of $C$. difficile. The role of $C$. difficile in IBS and co-occurrence rates in particular would also benefit from further research. It remains to be determined if incomplete treatment of CDI 
might be associated with the development of IBS, or if ongoing IBS might increase the risk of acquiring $C$. difficile. Current clinical outcomes analyses using data from our uBiome citizen science cohort will further illuminate whether individuals diagnosed as having IBS have higher carriage rates of $C$. difficile, a finding previously reported in other studies [44]. Disturbance of the gut microbiome may therefore predispose patients with IBS to CDI and subsequent exacerbation of existing IBS symptoms due to the pathogen's toxigenic nature [43].

While our product (that is, SmartGut ${ }^{\mathrm{tm}}$ ) is not intended in any way to replace standard of care or to function as a diagnostic tool for acute infection, the use of an at-home clinical microbial screening test for pathogenic and commensal bacteria associated with chronic conditions is a minimally invasive testing option that may provide clinicians and patients with unique information that could positively impact time to treatment, as well as improve patient outcomes.

\section{Abbreviations}

BMI: Body mass index; CDI: Clostridium difficile infection; FODMAP: Fermentable oligosaccharides, disaccharides, monosaccharides, and polyols; GI: Gastrointestinal; IBD: Inflammatory bowel disease; IBS: Irritable bowel syndrome; IBS-C: Irritable bowel syndrome with constipation; IBS-D: Irritable bowel syndrome with diarrhea; IBS-M: Mixed irritable bowel syndrome; IBS-U: Unclassified irritable bowel syndrome; PCR: Polymerase chain reaction; rRNA: Ribosomal RNA

\section{Acknowledgements}

We especially want to thank the patient for agreeing to share her case. We also thank uBiome's: research and development (R\&D) team members Cristian Bravo, Jillian DeBlanc, Kira Harman, and Juan Jimenez; algorithm development team members - Raul Arias and Felipe Melis; and the data science team members - Camila Navas and Sandro Valenzuela for their valuable contributions.

\section{Funding}

uBiome, Inc. funded the: study design, collection, analysis, and interpretation of data; writing of the paper; and decision to submit for publication.

\section{Availability of data and materials}

Not applicable.

\section{Authors' contributions}

$\mathrm{MH}$ performed literature review and drafted the manuscript. ET carried out the patient's interview, follow-up, and drafted case presentation. SG, CP, and $\mathrm{MCH}$ helped to draft the manuscript. EMB edited the manuscript. DEA, JR and ZSA designed the study, edited, read, and approved the final manuscript. All authors read and approved the final manuscript.

\section{Ethics approval and consent to participate}

The patient gave consent under Institutional Review Board (IRB), Study \#2016-440A, 06/08/2018, Asentral, Inc.

\section{Consent for publication}

Written informed consent for publication of her clinical details and/or clinical images was obtained from the patient. A copy of the consent form is available for review by the Editor-in-Chief of this journal.

\section{Competing interests}

All authors are or were full-time employees of, or consultants to, uBiome, Inc.

\section{Publisher's Note}

Springer Nature remains neutral with regard to jurisdictional claims in published maps and institutional affiliations.

Received: 29 June 2018 Accepted: 7 November 2018

Published online: 15 January 2019

\section{References}

1. Qin J, Li R, Raes J, Arumugam M, Burgdorf KS, Manichanh C, et al. A human gut microbial gene catalogue established by metagenomic sequencing. Nature. 2010:464(7285):59-65.

2. Clarke G, Stilling RM, Kennedy PJ, Stanton C, Cryan JF, Dinan TG. Minireview: Gut microbiota: the neglected endocrine organ. Mol Endocrinol. 2014;28(8): $1221-38$.

3. Bäckhed F, Fraser CM, Ringel Y, Sanders ME, Sartor RB, Sherman PM, et al. Defining a Healthy Human Gut Microbiome: Current Concepts, Future Directions, and Clinical Applications. Cell Host Microbe. 2012;12(5):611-22.

4. Lozupone CA, Stombaugh Jl, Gordon Jl, Jansson JK, Knight R. Diversity, stability and resilience of the human gut microbiota. Nature. 2012;489(7415): 220-30

5. Mosca A, Leclerc M, Hugot JP. Gut Microbiota Diversity and Human Diseases: Should We Reintroduce Key Predators in Our Ecosystem? Front Microbiol. 2016;7 Available from: https://www.ncbi.nlm.nih.gov/pmc/articles/ PMC4815357/. [cited 2018 May 15]

6. Hawrelak JA, Myers SP. The Causes of Intestinal Dysbiosis: A Review. Altern Med Rev. 2004:9(2):180-97.

7. Cremon C, Carini G, Giorgio RD, Stanghellini V, Corinaldesi R, Barbara G. Intestinal dysbiosis in irritable bowel syndrome: etiological factor or epiphenomenon? Expert Rev Mol Diagnostics. 2010;10(4):389-93.

8. Bien J, Palagani V, Bozko P. The intestinal microbiota dysbiosis and Clostridium difficile infection: is there a relationship with inflammatory bowel disease? Therap Adv Gastroenterol. 2013;6(1):53-68.

9. Larsen N, Vogensen FK, van den Berg FWJ, Nielsen DS, Andreasen AS, Pedersen BK, et al. Gut Microbiota in Human Adults with Type 2 Diabetes Differs from Non-Diabetic Adults. PLoS ONE. 2010;5(2):e9085.

10. Lippert K, Kedenko L, Antonielli L, Kedenko I, Gemeier C, Leitner M, et al. Gut microbiota dysbiosis associated with glucose metabolism disorders and the metabolic syndrome in older adults. Beneficial Microbes. 2017:8(4):545-56.

11. Saltzman ET, Palacios T, Thomsen M, Vitetta L. Intestinal Microbiome Shifts, Dysbiosis, Inflammation, and Non-alcoholic Fatty Liver Disease. Front Microbiol. 2018;9 Available from: https://www.ncbi.nlm.nih.gov/pmc/articles/ PMC5797576/. [cited 2018 May 15]

12. Lau K, Srivatsav V, Rizwan A, Nashed A, Liu R, Shen R, et al. Bridging the Gap between Gut Microbial Dysbiosis and Cardiovascular Diseases. Nutrients. 2017;9(8) Available from: https://www.ncbi.nlm.nih.gov/pmc/articles/ PMC5579652/. [cited 2018 May 15]

13. Suryavanshi MV, Bhute SS, Jadhav SD, Bhatia MS, Gune RP, Shouche YS Hyperoxaluria leads to dysbiosis and drives selective enrichment of oxalate metabolizing bacterial species in recurrent kidney stone endures. Sci Rep. 2016;6 Available from: https://www.ncbi.nlm.nih.gov/pmc/articles/ PMC5052600/. [cited 2018 May 15]

14. Moon Y. Microbiome-Linked Crosstalk in the Gastrointestinal Exposome towards Host Health and Disease. Pediatr Gastroenterol Hepatol Nutr. 2016; 19(4):221-8.

15. David LA, Maurice CF, Carmody RN, Gootenberg DB, Button JE, Wolfe BE, et al. Diet rapidly and reproducibly alters the human gut microbiome. Nature. 2014;505(7484):559-63.

16. Zhernakova A, Kurilshikov A, Bonder MJ, Tigchelaar EF, Schirmer M, Vatanen $T$, et al. Population-based metagenomics analysis reveals markers for gut microbiome composition and diversity. Science. 2016;352(6285):565-9.

17. Falony $\mathrm{G}$, Joossens $\mathrm{M}$, Vieira-Silva S, Wang J, Darzi Y, Faust K, et al. Population-level analysis of gut microbiome variation. Science. 2016; 352(6285):560-4.

18. Lankelma JM, Nieuwdorp M, de Vos WM, Wiersinga WJ. The gut microbiota in internal medicine: implications for health and disease. Neth J Med. 2015; 73(2):61-8.

19. Canavan C, West J, Card T. The epidemiology of irritable bowel syndrome. Clin Epidemiol. 2014;6:71-80.

20. Qin $\mathrm{H}-\mathrm{Y}$, Cheng C-W, Tang X-D, Bian Z-X. Impact of psychological stress on irritable bowel syndrome. World J Gastroenterol. 2014;20(39):14126-31. 
21. Saha L. Irritable bowel syndrome: pathogenesis, diagnosis, treatment, and evidence-based medicine. World J Gastroenterol. 2014;20(22):6759-73.

22. Chey WD, Kurlander J, Eswaran S. Irritable bowel syndrome: a clinical review. JAMA. 2015;313(9):949-58.

23. Schmulson MJ, Drossman DA. What Is New in Rome IV. J Neurogastroenterol Motil. 2017;23(2):151-63.

24. Shepherd SJ, Parker FC, Muir JG, Gibson PR. Dietary triggers of abdominal symptoms in patients with irritable bowel syndrome: randomized placebocontrolled evidence. Clin Gastroenterol Hepatol. 2008;6(7):765-71.

25. Halmos EP, Power VA, Shepherd SJ, Gibson PR, Muir JG. A diet low in FODMAPs reduces symptoms of irritable bowel syndrome. Gastroenterology. 2014;146(1):67-75. e5

26. Moser G, Fournier C, Peter J. Intestinal microbiome-gut-brain axis and irritable bowel syndrome. Wien Med Wochenschr. 2018;168(3-4):62-6.

27. Hungin APS, Chang L, Locke GR, Dennis EH, Barghout V. Irritable bowel syndrome in the United States: prevalence, symptom patterns and impact. Aliment Pharmacol Ther. 2005;21(11):1365-75.

28. Collins SM. A role for the gut microbiota in IBS. Nat Rev Gastroenterol Hepatol. 2014;11(8):497-505.

29. Ringel Y, Ringel-Kulka T. The Intestinal Microbiota and Irritable Bowel Syndrome. J Clin Gastroenterol. 2015;49(Suppl 1):S56-9.

30. Collins SM. The Intestinal Microbiota in the Irritable Bowel Syndrome. Int Rev Neurobiol. 2016;131:247-61. https://doi.org/10.1016/bs.irn.2016.08.003.

31. Bhattarai Y, Muniz Pedrogo DA, Kashyap PC. Irritable bowel syndrome: a gut microbiota-related disorder? Am J Physiol Gastrointest Liver Physiol. 2016; 312(1):G52-62.

32. Malinen E, Rinttilä T, Kajander K, Mättö J, Kassinen A, Krogius L, et al. Analysis of the fecal microbiota of irritable bowel syndrome patients and healthy controls with real-time PCR. Am J Gastroenterol. 2005;100(2):373-82.

33. Malinen E, Krogius-Kurikka L, Lyra A, Nikkilä J, Jääskeläinen A, Rinttilä T, et al. Association of symptoms with gastrointestinal microbiota in irritable bowel syndrome. World J Gastroenterol. 2010;16(36):4532-40.

34. Kassinen A, Krogius-Kurikka L, Mäkivuokko H, Rinttilä T, Paulin L, Corander J, et al. The fecal microbiota of irritable bowel syndrome patients differs significantly from that of healthy subjects. Gastroenterology. 2007;133(1):24-33.

35. Jalanka-Tuovinen J, Salojärvi J, Salonen A, Immonen O, Garsed K, Kelly FM, et al. Faecal microbiota composition and host-microbe cross-talk following gastroenteritis and in postinfectious irritable bowel syndrome. Gut. 2014; 63(11):1737-45.

36. Khanna S, Pardi DS. The growing incidence and severity of Clostridium difficile infection in inpatient and outpatient settings. Expert Rev Gastroenterol Hepatol. 2010;4(4):409-16.

37. Loo VG, Bourgault A-M, Poirier L, Lamothe F, Michaud S, Turgeon N, et al. Host and pathogen factors for Clostridium difficile infection and colonization. N Engl J Med. 2011;365(18):1693-703.

38. Khanna S, Pardi DS. Clinical implications of antibiotic impact on gastrointestinal microbiota and Clostridium difficile infection. Expert Rev Gastroenterol Hepatol. 2016;16:1-8. https://doi.org/10.1586/17474124.2016. 1158097.

39. Lessa FC, Mu Y, Bamberg WM, Beldavs ZG, Dumyati GK, Dunn JR, et al. Burden of Clostridium difficile Infection in the United States. New Engl J Med. 2015;372(9):825-34.

40. Di Bella S, Ascenzi P, Siarakas S, Petrosillo N, di Masi A. Clostridium difficile Toxins A and B: Insights into Pathogenic Properties and Extraintestinal Effects. Toxins (Basel). 2016;8(5) Available from: https://www.ncbi.nlm.nih. gov/pmc/articles/PMC4885049/. [cited 2018 Feb 14]

41. Tschudin-Sutter S, Carroll KC, Tamma PD, Sudekum ML, Frei R, Widmer AF, et al. Impact of Toxigenic Clostridium difficile Colonization on the Risk of Subsequent C. difficile Infection in Intensive Care Unit Patients. Infect Control Hosp Epidemiol. 2015;36(11):1324-9.

42. Furuya-Kanamori L, Marquess J, Yakob L, Riley TV, Paterson DL, Foster NF, et al. Asymptomatic Clostridium difficile colonization: epidemiology and clinical implications. BMC Infect Dis. 2015;15 Available from: https://www.ncbi.nlm. nih.gov/pmc/articles/PMC4647607/. [cited 2018 Oct 25]

43. Wadhwa A, Al Nahhas MF, Dierkhising RA, Patel R, Kashyap P, Pardi DS, et al. High risk of post-infectious irritable bowel syndrome in patients with Clostridium difficile infection. Aliment Pharmacol Ther. 2016;44(6):576-82.

44. Clayton EM, Rea MC, Shanahan F, Quigley EMM, Kiely B, Ross RP, et al. Carriage of Clostridium difficile in outpatients with irritable bowel syndrome. J Med Microbiol. 2012;61(9):1290-4.
45. Almonacid DE, Kraal L, Ossandon FJ, Budovskaya YV, Cardenas JP, Bik EM, et al. $16 \mathrm{~S}$ rRNA gene sequencing and healthy reference ranges for 28 clinically relevant microbial taxa from the human gut microbiome. PLOS ONE. 2017; 12(5):e0176555.

46. Vecchio AL, Zacur GM. Clostridium difficile: an update on epidemiology, risk factors, and therapeutic options infection: an update on epidemiology, risk factors, and therapeutic options. Curr Opin Gastroenterol. 2012;28(1):1-9.

47. Theriot CM, Young VB. Interactions Between the Gastrointestinal Microbiome and Clostridium difficile. Ann Rev Microbiol. 2015;69(1):445-61.

48. Britton RA, Young VB. Role of the Intestinal Microbiota in Resistance to Colonization by Clostridium difficile. Gastroenterology. 2014;146(6):1547-53.

49. Lawes T, Lopez-Lozano J-M, Nebot CA, Macartney G, Subbarao-Sharma R, Wares KD, et al. Effect of a national $4 \mathrm{C}$ antibiotic stewardship intervention on the clinical and molecular epidemiology of Clostridium difficile infections in a region of Scotland: a non-linear time-series analysis. Lancet Infect Dis. 2017;17(2):194-206.

50. Basseri RJ, Weitsman S, Barlow GM, Pimentel M. Antibiotics for the Treatment of Irritable Bowel Syndrome. Gastroenterol Hepatol (N Y). 2011; 7(7):455-93

\section{Ready to submit your research? Choose BMC and benefit from:}

- fast, convenient online submission

- thorough peer review by experienced researchers in your field

- rapid publication on acceptance

- support for research data, including large and complex data types

- gold Open Access which fosters wider collaboration and increased citations

- maximum visibility for your research: over $100 \mathrm{M}$ website views per year

At $\mathrm{BMC}$, research is always in progress.

Learn more biomedcentral.com/submissions 